\title{
Diálogos transnacionais entre Uruguai, América do Sul e Estados Unidos: a preparação de diretores de Educação Física pela Associação Cristã de Moços
}

\section{Transnational dialogues between Uruguay, South America and the United States: the training of YMCA's physical education directors}

\author{
Paola Dogliotti \\ Orcid: https://orcid.org/0000-0002-1913-8099 \\ Universidad de la República, Montevideo, \\ Uruguay paoladogliottimoro@gmail.com \\ Giovanna Camila da Silva \\ Orcid: https://orcid.org/0000-0002-5705-0573 \\ Universidad Federal de Minas Gerais, Belo \\ Horizonte, Brasil, \\ giovannaufmg@yahoo.com.br
}

DOI: 10.21680/2596-0113.2021v4n0ID25762

Citation: Dogliotti, P. \& Silva, G. C. da. (2021). Diálogos transnacionais entre Uruguai, América do Sul e Estados Unidos: a preparação de diretores de Educação Física pela Associação Cristã de Moços. History of Education in Latin America - HistELA, 4, e25762.

Competing interests: The authors have declared that no competing interests exist.

Editor: Maria Inês Sucupira Stamatto

Received: 29/06/2021

Approved: 29/10/2021

\section{OPEN ACCESS}

\begin{abstract}
Resumo
Este estudo investigou os cursos de formação de diretores de Educação Física promovidos pela Associação Cristã de Moços (ACM), na década de 1920, em dois locais institucionais: o The Young Men's Christian Association College, em Chicago, e o Instituto Técnico Sudamericano de la Asociación Cristiana de Jóvenes, em Montevidéu. Ao adotar elementos de análise das histórias conectadas, o objetivo foi analisar as trocas estabelecidas pela própria ACM em seus institutos localizados em diferentes lugares da América. Documentos institucionais constituíram-se como fontes privilegiadas na pesquisa e permitiram apreender um processo de circulação de saberes e práticas na Associação mediado por negociados exercícios de sistematização.
\end{abstract}

Palavras-chave: História da Educação. Educação Física. Formação. Circulação. Associação Cristã de Moços.

\begin{abstract}
This study investigated the training courses for Physical Education directors promoted by the Young Men's Christian Association (YMCA), in the 1920s, in two institutional places: The Young Men's Christian Association College, in Chicago and the Instituto Técnico Sudamericano de la Asociación Cristiana de Jóvenes in Montevideo. In the research elements of analysis of the connected stories were adopted to analyze the exchanges established by the ACM itself in its institutes located in different countries in America. The sources mobilized for this project were official documents. It was possible to apprehend a process of circulation of knowledge and practices in the Association mediated by negotiated systematization exercises.
\end{abstract}

Keywords: History of Education. Physical Education. Training. Circulation. Young Men's Christian Association. 


\section{Introdução}

Entre os anos finais do século $\mathrm{XIX}$ e as décadas iniciais do século $X X$, a Associação Cristã de Moços (ACM) empreendeu uma expansão de seu projeto formador na América do Sul a partir da implantação de sedes em diversos países. Ainda que, desde sua criação, a Associação demandasse investimentos nos e sobre os corpos dos sujeitos, foi com o desenvolvimento de suas ações que a dimensão física foi tornando-se cada vez mais um lugar de intervenção da Associação. Esse processo promoveu a participação de acemistas em diferentes projetos, dentro e fora da instituição, que impulsionaram o desenvolvimento do esporte e da Educação Física no Brasil (Baia \& Moreno, 2019; Silva, 2017, 2018, 2019); na Argentina (Ainsentein \& Elías, 2018) e no Uruguai (Couchet et al., 2013; Dogliotti, 2014, 2015a, 2015b). O processo inicial de secularização e laicização permitiu ao Estado uruguaio criar laços estreitos com esta Associação de base protestante, o que resultou na intensa participação da ACM na institucionalização da Educação Física nacional (Dogliotti \& Malán, 2015; Malán, 2017, 2018, 2019).

Interessado nas conexões entre cursos de preparação em Educação Física empreendidos pela ACM nos Estados Unidos e no Uruguai, este estudo investigou a formação de diretores físicos promovidos pela Associação Cristã de Moços, na década de 1920, em dois locais institucionais: o The Young Men's Christian Association College, em Chicago, e o Instituto Técnico Sudamericano de la Asociación Cristiana de Jóvenes, em Montevidéu. Ao adotar pressupostos das "histórias conectadas" (Fonseca, 2012; Gruzinski, 2015), nosso propósito é dar visibilidade para um fluxo de sentidos que permearam a formação de diretores físicos nas trocas estabelecidas pela própria ACM entre seus diferentes institutos. Trocas essas que podem comportar choques, conflitos, rejeição e/ou adesão, colaborações e exercícios de negociação de valores, interesses, significados. No projeto formador acemista, a direção em Educação Física foi desenhando-se como profissão ao longo do tempo, relacionada à entrada mais decisiva da cultura física nos empreendimentos da instituição. A escola de treinamento profissional da Associação em Chicago foi inaugurada em 1884 e, ao longo do tempo, passou por diferentes transformações em sua estrutura e no desenho do curso ali oferecido para a preparação de diretores físicos. Preocupada com a produção de referências pedagógicas e culturais para atender às especificidades dos países sul-americanos, a Associação Cristã de Moços estabeleceu em Montevidéu, no ano de 1922, o Instituto Técnico Sul-Americano como instância formadora de seus agentes.

Nosso intuito foi perceber se e como as experiências de qualificação estadunidenses constituíram-se como canal de diálogo e referência para a formação de diretores especializados em Educação Física que estudariam na América do Sul. Os documentos institucionais constituíram-se como fontes privilegiadas na investigação. Optamos por uma narrativa que aborda inicialmente o curso de preparação em Chicago e, em seguida, tematiza o processo de formação em Montevidéu, mobilizando eixos de análise comuns como a necessidade de criação desses estabelecimentos, os mecanismos de seleção dos estudantes, os saberes privilegiados no plano de estudos e a constituição de uma profissão com identidade acemista.

\section{Em Chicago, no Young Men's Christian Association College}

O Young Men's Christian Association College, assim designado a partir de 1913, foi resultado do anseio de líderes da Associação do Meio-Oeste dos Estados 
Unidos que demandavam o treinamento profissional de seu quadro funcional. Iniciado sob a nomeação Western Secretarial Institute, em 1884, teve o nome mudado para The Young Men's Christian Association Training School em 1890. O propósito do Instituto consistia no treinamento, educação e ajuste de secretários e diretores físicos da ACM, "instruindo-os na palavra de Deus e na prática da Associação Cristã de Moços" (YMCA, 1920, p. 18, tradução livre). A possibilidade de investigar tal lugar institucional apresentou-se a partir de indícios que anunciavam a formação de brasileiros pela Associação em Chicago. Esse vestígio produziu um movimento de composição de fontes no Kautz Family YMCA Archives, na Universidade de Minnesota, que organiza, preserva e fornece acesso à documentação da Young Men's Christian Association (YMCA) nos Estados Unidos e nos demais países em que a instituição constituiu sedes.

A configuração da preparação técnica na instituição de formação da YMCA em Chicago sofreu modificações ao longo de seu funcionamento: mudanças de denominação, alterações de espaço e de estrutura, transformações no plano de estudos. Para a análise agora proposta, a instituição foi investigada nos anos de 1919 a 1921. Esta opção justifica-se por este período se aproximar da data de fundação do Instituto Técnico das Associações Cristãs de Moços em Montevidéu, em 1922.

O College em Chicago oferecia diferentes especializações profissionais. Além de administração geral e Educação Física, os estudantes poderiam formar-se nos cursos de boy's work, county work, community work, industrial work, transportation work, que, sublocados na administração secretarial, compreenderiam diferentes fases do trabalho da Associação. Nos requisitos para admissão, a instituição apresenta as qualificações exigidas para o secretariado da Associação:
a. Boa saúde e uma personalidade atraente.
b. Capacidade de fazer e manter amigos, habilidade de cooperar com os outros e liberdade de excentricidades marcadas no hábito, maneira ou aparência.
c. Senso de boa conduta e bom senso, com potencial capacidade executiva, iniciativa e tato.
d. Uma educação liberal, de preferência um curso de faculdade ou seu equivalente, com a vontade de procurar qualquer formação e experiência profissional especial, pode ser necessária.
e. Adesão leal a uma igreja evangélica, forte caráter e conviç̧ões cristãs, liderança religiosa, um propósito de sacrifício e capacidade de ajudar religiosamente jovens e meninos.
f. Ausência da menor sugestão de delinquência moral. É absolutamente essencial que um líder da Associação, por causa de seu contato íntimo com homens e meninos, seja moralmente acima de qualquer reprovação (YMCA, 1921, p. 29, tradução livre).

As condições para candidatura ao curso explicitavam eixos orientadores do projeto acemista antes mesmo do início da formação. Saúde, capacidade executiva, repertório de saberes, religiosidade, altruísmo, moralidade compunham elementos de uma identidade institucional. A Associação dizia que a demanda não era por mais homens, mas por aqueles que tivessem tais capacidades e aspectos de personalidade. Deixar evidente as características exigidas para admissão no curso era também dizer que assumir funções no interior da ACM não era para qualquer um, mas para um arranjo de líderes que a Associação pretendia formar.

Para a preparação dos estudantes, eram quatro os departamentos de instrução: ciência da Associação (responsável pelos estudos em administração geral, boy's work, county work, community work, industrial work, transportation work e 
inglês); religião e ética (encarregado pelos estudos da bíblia, da igreja cristã e de educação religiosa); ciência social (responsável pela instrução em psicologia, sociologia e economia); e ciência física (incumbido da educação física, da biologia compreendendo zoologia, anatomia, fisiologia e higiene - e das atividades físicas).

A formação para diretores físicos totalizaria quatro anos de preparação. Durante os dois primeiros anos todos os alunos teriam as mesmas matérias, e, em seguida, aconteceriam as especializações para cada curso. $O$ ano acadêmico era composto por três períodos - outono, inverno e primavera - de 11 a 12 semanas cada.

Do plano proposto para a preparação técnica em Educação Física (YMCA, 1921), vale ressaltar uma dimensão educativa que incorporava questões sociais. $O$ debate relativo às atualidades, à organização da sociedade, a condutas de referência, vinculava-se às matérias intituladas "problemas sociais" e "campo, história e princípios da Educação Física", presentes no primeiro trimestre do terceiro ano. Destaque-se a discussão referente às condições prejudiciais da época que causavam ineficiência física, tais como as industriais e as recreativas.

\begin{abstract}
Um curso geral, com o intuito de dar ao aluno alguma familiaridade prática com os problemas pendentes [...] que confrontam a sociedade contemporânea, particularmente os que foram acentuados pela guerra, juntamente com os esforços de solução que têm se desenvolvido. Entre os temas considerados estão: dependência, deficiência, delinquência, crime, vício, bem-estar infantil, desintegração familiar, padrões de vida, recreação, saúde pública, segurança e saneamento. São feitas investigações sobre o trabalho das agências locais de socorro e melhoria social. Cada aluno é obrigado a realizar um estudo pessoal dos métodos de pelo menos uma organização líder de serviços sociais de Chicago e apresentar à classe um relatório formal (YMCA, 1921, p. 47, tradução livre).
\end{abstract}

Na preparação dos diretores físicos, é possível destacar a expectativa de não restringir sua ação à dimensão física, mas de abranger o corpo social, ou, de modo mais contundente, intervir no físico para a vida social. Seja nas ações no interior das Associações, seja nas iniciativas de acemistas que atuavam em outros espaços, a demanda pela ocupação do tempo livre para evitar a delinquência, o jogo como necessidade da criança, a prática de exercícios físicos para a manutenção da saúde, o caráter moralizador envolvido no desenvolvimento corporal, são elementos que compõem a tessitura que envolvia o físico e a vida social. Operando com essa trama, a preparação no College não se restringia aos seus intramuros. A relação com o entorno social era considerada de valor inestimável na educação dos estudantes. "As relações com a comunidade - os variados e únicos elementos, as agências e as influências constitutivas da vida urbana moderna são fatores valiosos em uma educação liberal" (YMCA, 1920, p. 21, tradução livre). A cidade era considerada um laboratório social, uma estação de observação onde grandes questões relacionadas aos aspectos comercial, industrial, político, econômico, educacional, religioso e filantrópico poderiam estar mais visíveis. "O que é característico das cidades em geral é particularmente verdadeiro em Chicago", anunciava o College (YMCA, 1920, p. 22, tradução livre). Na relação com a cidade, os alunos teriam a oportunidade de exercer sua "vocação". Igrejas, escolas, faculdades, organizações sociais, playgrounds configuravam-se como laboratórios práticos para o secretariado em formação.

Todo esse processo formativo no College tinha um custo. Para estudantes estrangeiros que vislumbravam retornar aos países de origem e trabalhar na Associação Cristã de Moços, bolsas de estudos eram uma possibilidade de terem 
diminuídas as despesas com a formação nos Estados Unidos. As bolsas eram mantidas por um fundo especial composto por associações interessadas, amigos, comitês nacionais e internacionais. Algumas orientações regulavam o processo de distribuição do auxílio: o pedido deveria ser feito antecipadamente em formulário especial, o candidato deveria ser aprovado pelo College e pelo comitê nacional do país de origem ou pelo departamento de trabalho estrangeiro do comitê internacional, e a bolsa poderia ser suspensa, mediante aviso prévio, caso houvesse alguma razão suficiente que levasse o College ou os comitês nacional ou internacional a interromper o subsídio ao aluno (YMCA, 1921). No estabelecimento de assistência aos estudantes estrangeiros, a expectativa da Associação era a de que o aporte financeiro investido na formação retornasse em benefício próprio quando, formados como secretários gerais, diretores físicos ou outras especialidades, pudessem ocupar cargos nas ACM's. A Associação parecia não prever, de início, os desvios nas trajetórias individuais e a complexidade na composição dos campos profissionais.

Durante muito tempo, as sedes das Associações, notadamente as sulamericanas, constituíram-se a partir do trabalho de secretariado formado nas escolas de preparação existentes nos Estados Unidos. Contudo, havia uma expectativa tanto de dirigentes de países da América do Sul quanto do Comitê Internacional que o projeto da ACM fosse realizado por homens com nacionalidade do local onde a sede estava instalada. Nesse sentido, a instalação de um instituto sul-americano que cuidasse da formação do secretariado acemista era o caminho a ser trilhado. Essa criação fundamentava-se ainda pelas razões que dificultavam a ida aos Estados Unidos de jovens interessados nos cursos de secretariado da YMCA. A dificuldade em recrutar um número suficiente de homens com características adequadas ao cargo e que se dispusessem a passar anos de estudos em outro país, o alto custo dessa formação, e a alta taxa de desistência compunham o conjunto dos obstáculos.

\section{Em Montevidéu, o Instituto Técnico Sudamericano de la Asociación Cristiana de Jóvenes (ITSACJ)}

O Instituto foi criado em 1922 pela Federação Sul-Americana da ACM e sua sede foi radicada na cidade de Montevidéu. Recebia líderes do Uruguai, da Argentina, Brasil, Chile, Peru, México. Os dois primeiros anos do curso de formação eram realizados nas ACM's locais e os dois últimos na sede. Em 1927, tempos antes de retornar ao seu país, após uma longa carreira no Uruguai e cinco anos após a criação do Instituto, Jess T. Hopkins ${ }^{1}$ declara:

Después de muchos años de estudio y ante una necesidad sin cesar creciente de preparación y entrenamiento de líderes nacionales, se estableció en el año 1922 el Instituto Técnico. (...) Este esfuerzo representa, fuera de duda, el acontecimiento más importante producido en el desarrollo de nuestra obra en Sud América. El establecimiento de la Escuela ha tenido una influencia vital y estimuladora sobre todo el movimiento en general y especialmente sobre aquellos secretarios y directores de Educación Física encargados de la enseñanza específica. El sistema continental de preparación se está identificando con el movimiento de la Asociación en una forma muchísimo más profunda y significativa que nuestras escuelas profesionales de Estados Unidos (Hopkins, 1927, p. 52, grifos nossos).

A fermentação desse processo e a congregação de vários países foram fatores que contribuíram para que Hopkins concedesse ao Instituto Técnico uma identidade 
em relação ao movimento acemista maior do que o das "escolas profissionais" nos Estados Unidos. Hopkins hierarquizava a formação do Instituto em relação à importância e especificidade da disciplina que se ensinava, Educação Física. As redes internacionais tecidas entre os acemistas de diferentes países latino-americanos para conduzir a ideia do ITSACJ caracteriza a missão e o expansionismo associacionista. Tais redes compreendiam a circulação de ideias, sujeitos e diversos objetos materiais. A análise das fontes permite indicar que ressoava dos Estados Unidos muitas das ideias em trânsito, ainda que, ao chegar em diferentes países da América do Sul, processos de apropriação e articulação foram experimentados em cada lugar. No processo de implementação do Instituto Técnico foram também estabelecidas estratégias de intercâmbio entre os países sul-americanos e produzidos processos de apropriação particulares, percebidos pelos atores locais de forma mais "profunda e significativa" do que nos Estados Unidos, conforme destacado na citação anterior.

Em carta enviada aos Secretários Internacionais da América do Sul, em 23 de dezembro de 1921, sobre o tema "preparativos para implementar o plano de formação" do Instituto Técnico, Carlos J. Ewald ${ }^{2}$ expressou que durante a viagem pela América do Sul discutiram o "Plano de Treinamento", que foi finalmente adotado pelo Comitê Continental e detalha os seguintes aspectos:

- 4 anos de curso tanto para secretários como para diretores físicos;

- $1^{\circ}$ e $2^{\circ}$ ano nas escolas locais, $3^{\circ}$ e $4^{\circ}$ no Continental Training College, que seria estabelecido em Montevidéu;

- O Sr. Conard assumiria o plano geral;

- J. S. Summers, diretor do curso de Educação Física, chegaria a Montevidéu em fevereiro de 1922 (Ewald, 1921).

Felipe Conard, primeiro diretor do Instituto Técnico, cargo que ocupou até 1931 quando assumiu como secretário-geral da Confederação Sul-Americana da ACJ até 1940, expressou:

\begin{abstract}
Ya designado por la Junta en 1920 como Director Organizador del Instituto Técnico a establecerse, de acuerdo con la resolución de la 2a ${ }^{-}$Convención Continental de 1919, pasé un tiempo en Norteamérica visitando instituciones y educadores, estudiando programas de materias, formando la biblioteca, consultando sobre personal docente, etc. (Conard, 1959, p. 60).
\end{abstract}

Destaca-se a referência que foi o treinamento realizado nos Estados Unidos, possivelmente nas escolas profissionais que a ACM ali mantinha, para 0 desenvolvimento do ITSACJ. Não apenas vários professores do Instituto foram treinados nessas escolas, mas seus criadores as tomaram como exemplo para montar os programas, os critérios de seleção de seus alunos, os modos gerais de organização do Instituto, entre os aspectos mais importantes.

James Stewart Summers, australiano, formou-se como mestre em Educação Física pela Universidade de Springfield. Como diretor continental de Educação Física das Associações Cristãs de Moços da América do Sul, viajou para Montevidéu em 1922 para assumir a direção do curso de Educação Física no Instituto Técnico. 
Com relação aos requisitos de ingresso no Instituto, na ata de 2 de fevereiro de 1923 da reunião anual da Junta Continental realizada em Piriápolis no Uruguai, explicitam-se como exigências:

una preparación cultural equivalente a la exigida para el ingreso a las facultades universitarias. Tal capacidad se prueba mediante un examen rendido ante una mesa designada por la Comisión Local. El examen versará necesariamente sobre los siguientes puntos: a) Redacción de una composición en la lengua nacional, sobre un tema histórico. El objeto de esta composición será juzgar en primer lugar la capacidad del alumno en el manejo del idioma, en segundo, sus conocimientos de historia; en tercero, sus orientaciones ideológicas. b) Lectura y traducción oral de una página de un autor contemporáneo de lengua inglesa. c) Examen oral de ciencias físiconaturales. d) Resolución de problemas de aritmética, Álgebra y Geometría. Además se exige un examen médico a todo candidato (FSACJ, 1923, p. 4).

Embora se pretendesse conceder ao Instituto um nível universitário, o diploma nunca foi reconhecido como tal. Ao mesmo tempo em que era indicado um requisito equivalente ao estudante universitário, o comprovante de bacharelado completo não era necessário. No processo de seleção, diferentes aspectos são apresentados como importantes. Por um lado, mostra-se a relevância atribuída a elementos de cultura geral (domínio da língua e conhecimentos históricos), mas vinculados às "orientações ideológicas" dos candidatos. Daí a marca associacionista, movimento que se identificava com certas ideias, crenças e preceitos de sua própria organização. O item 'b' reforça os vestígios sobre a base e inspiração da proposta ancoradas nas escolas profissionais dos Estados Unidos. Dominar a língua inglesa poderia configurar-se como necessidade para compreensão do programa de ensino dos cursos, seja pelo contato com sujeitos provenientes de outros países, seja pelo contato com aparatos textuais em língua estrangeira. Em relação aos pontos 'c' e 'd', as ciências físiconaturais e matemáticas configuravam-se como necessárias, por um lado, para os estudos em administração que o movimento associacionista deu relevância, e por outro, para os estudos estatísticos e antropométricos centrados no corpo orgânico que se seguiriam na atuação do diretor físico. O que é reafirmado com a relevância do controle corporal por meio do exame médico. Controles que não se referiam apenas às dimensões físicas do corpo, mas "condições morais do candidato" também eram constantemente avaliadas, o que se soma à supervisão das "orientações ideológicas" anteriormente analisadas. Isso é também indicado na ata: "La Comisión Local está obligada a juzgar las condiciones morales positivas de cada alumno, al fin de cada año, a base de los informes de la comisión. El alumno que no tenga por lo menos $2 / 3$ de votos favorables en dicha comisión, no podrá proseguir sus estudios en el Instituto" (FSACJ, 1923, p. 5). O controle exercido pelas autoridades implicava vigilância constante e minuciosa sobre cada aluno. $O$ discurso normalista é um componente da formação. As atitudes morais, juntamente com outras, ocuparam um lugar relevante, não apenas como um mecanismo de seleção de "candidatos", mas durante todo o processo de treinamento, a ponto de "julgar" e "expulsar" os estudantes por supostas razões "morais". Isso é reforçado ao considerar que, nos últimos dois anos, havia um sistema de convivência no lar onde os estudantes estrangeiros hospedavam-se.

Em relação ao programa de estudos, de acordo com a ata de 1923, seriam doze grupos de disciplinas: "Biológicas, Educación Religiosa, Técnicas de la Asociación Cristiana de Jóvenes, Sociológicas, Higiene y Anexos, Psicológicas, Idiomas y Literatura, Pedagógicas, Filosóficas, Históricas, Teoría y Práctica de Actividades Físicas y Trabajo práctico bajo su supervisión" (FSACJ, 1923, p. 4). A 
formação, de modo similar àquela oferecida em Chicago, era ampla e variada. Compreendia matérias tanto da área biológica quanto das ciências sociais e humanas, além de aspectos religiosos e técnicos que estruturavam a identidade da Associação. Do "Registro individual do aluno" do Instituto Técnico das Associações Cristãs de Jovens (ITACJ, 1922), analisamos a lista de disciplinas dos quatro anos do curso de Educação Física, distribuídas por trimestres (I, II, III).

As matérias relativas às ciências biológicas e médicas, à Educação Física, à educação cristã e às ciências da administração e associacionismo estruturam a formação ministrada no curso de Educação Física do Instituto Técnico. Destes quatro grupos, aqueles relativos à educação cristã e às ciências da administração e do associativismo reforçam a identidade da formação acemista e o distinguem de demais formações da área ${ }^{3}$. Ali eram enfatizadas a compreensão de liderança e a assimilação de aspectos missionários que estruturaram o movimento associacionista. A liderança configurou-se pela centralidade ocupada pelos valores cristãos e pela formação do "caráter" nas ações de serviço comunitário que se expandiram em diversos países da América do Sul, onde sedes da Associação foram instaladas, e conformou traços peculiares de seu modo de treinamento e missão.

$\mathrm{Na}$ análise das matérias, a necessidade de pensar sobre essa formação terciária de modo similar à uma formação básica é constatada: no grande número de matérias apresentadas pelo programa; no tratamento, de certo modo, escolarizante dos alunos (elaboração de julgamentos sobre seu comportamento moral); na ênfase dada à convivência e nas características de internato dos últimos dois anos de treinamento na Escola Continental.

Dos diversos documentos e matérias que compunham a formação dos diretores de Educação Física do Instituto Técnico, podemos dizer que se orientam por uma mistura de normalismo e tecnicismo. O primeiro, caracterizado por uma educação, mais que um ensino, em diferentes aspectos como: o cristão; as normas; os objetivos e os princípios acemistas; o higienismo; o espírito de serviço comunitário; a importância dada ao "caráter moral" e as condições de leadership para a seleção dos "candidatos"; o julgamento moral dos alunos durante os quatro anos de estudo; a importância atribuída aos aspectos de vínculo e convivência, tanto na vida em casa quanto no acampamento na escola de verão; e os assuntos presentes em seus programas. O tecnicismo é apresentado na figura do diretor físico como um administrador, executor, organizador de uma empresa. Portanto, a ênfase colocada em um importante núcleo de assuntos pertencentes às ciências da administração. Foi dada muita importância às horas dedicadas às práticas de Educação Física, com o entendimento de que o futuro professor ou diretor devia ser um bom executor ou modelo dos diferentes exercícios físicos. Por outro lado, ele também devia ter horas de prática de ensino ou "trabalho prático", o que permitiria obter experiência profissional. Nesse sentido, a formação foi orientada ao treinamento de um trabalhador, com forte vinculação com a prática profissional. A dimensão administrativa desempenhou um papel preponderante no modelo das ACM's. Seus departamentos de Educação Física deviam "servir como modelo, como centro administrativo y como la productora de dirección bien preparada", "lo más cercana posible al 100\% de eficiencia" (Hopkins, 1927, p. 33). Mas o eixo administrativo do diretor de Educação Física era complementado pelo "servicio comunitario" ou "de extensión de servicios técnicos" para outras instituições (escolas, governos, comissões nacionais de Educação Física, federações nacionais, Comitê Olímpico Internacional, treinamento de equipes olímpicas, praças de esportes, etc.) (Hopkins, 1927, p. 31). Em uma resolução da 1a Convenção Continental de 1914, está expresso 
Nosotros creemos que la Asociación que contrate un Director de Educación Física, debe hacerlo entendiéndose claramente que dicho director viene a desarrollar la educación física cristiana en el más alto grado posible, en la comunidad; que esto, puede ser hecho, no dirigiendo personalmente el mayor número de actividades, sino concentrando sus esfuerzos de enseñanza sobre un grupo de hombres capacitados, que a su turno darían clases dentro y fuera de la Asociación (Hopkins, 1927, p. 32).

A tarefa "comunitária" focada na Educação Física, por meio de um corpo de líderes capacitados pelos diretores egressos dos estabelecimentos de formação da YMCA nos Estados Unidos, foi uma das matrizes fundadoras do Instituto Técnico. "La Asociación nunca debiera vacilar en ofrecer sus servicios cuando se relacione con empresas patrióticas con las cuales simpatiza" (Hopkins, 1927, p. 34). O espírito patriótico é outro dos fortes componentes que deram, junto ao espírito cristão, sentido à missão acemista. A partir desses princípios, entende-se a grande colaboração conjunta entre a ACM de Montevidéu e a Comissão Nacional de Educação Física (CNEF) para promover, desenvolver e divulgar a Educação Física uruguaia. Jess Hopkins, assim que chegou ao Uruguai, em 1913, ocupou o cargo de Diretor Técnico da Comissão Nacional de Educação Física até 1920, ano em que foi substituído por seu discípulo Julio J. Rodríguez. Este foi enviado junto com outros três sujeitos para estudar no Springfield College e, em seu retorno, todos ocuparam cargos de liderança importantes no CNEF. Rodríguez foi diretor técnico da CNEF entre os anos de 1920 a 1956; Julio Pereyra foi diretor da Praça de Esportes no 2 e diretor de Educação Física Universitária e Escolar vinculado à Direção Técnica do CNEF; August H. Grassi foi diretor técnico departamental da CNEF em Canelones, antes de viajar para Springfield. Ao retornar viveu alguns anos em Santiago do Chile, assessorando a criação da sede da Associação Cristã de Moços e voltou ao Uruguai, em 1925, para assumir a direção do Departamento de Educação Física da ACM. Emilio Chiapella foi diretor da Praça de Esportes no 5 e, posteriormente, Inspetor de Educação Física em Campanha 4 , da CNEF.

Vale um destaque quando balizamos os programas de estudos constituídos para a formação em Chicago e para aquela promovida em Montevidéu: no instituto dos Estados Unidos, as matérias listadas no plano de ensino não explicitam uma relação com os espaços escolares de educação (YMCA, 1921). Já no Instituto Técnico, disciplinas evidenciam em seus títulos relações com instituições de educação formal: "Ciências biológicas e médicas: Fisiologia; Higiene Geral e Escolar", "Ciências da administração e associacionismo: Organização e Administração da Educação Física (na ACM, nas escolas e nos liceus)" (ITACJ, 1922, grifos nossos). A ocupação de cargos decorrentes de políticas educacionais foi um elemento comum aos diretores físicos de diferentes países sul-americanos formados pela Associação. No Uruguai, outra característica de expansão do movimento associativo foi sua grande capacidade de contato e estabelecimento de vínculos rápidos com as principais figuras políticas do país. A tradição laica e um presidente que se opunha à igreja católica e que estabelecia estreito contato com lideranças protestantes, foram fatores que permitiram a grande ascensão do associativismo na gênese da Educação Física estatal uruguaia. Este foi outro motivo pelo qual o Uruguai sediou a Escola Continental ITSACJ, que se constituiu como legado através do qual os acemistas poderiam começar a formar seus "quadros próprios" na Sul-América sem a necessidade de enviá-los para qualificaremse no país do norte.

No Brasil, a instalação do Instituto Técnico fez a ACM do Rio de Janeiro circular propaganda para despertar o interesse e promover a formação técnica de interessados em seu secretariado. O reclame foi divulgado no periódico oficial da 
Associação, em seguida a uma nota extensa referente à organização e aos cursos do Instituto. Estampado em letras destacadas por seu tamanho e ainda sublinhadas, a Associação anunciava: Uma profissão de futuro. Em seguida, ressaltava como uma estratégia para adesão de estudantes, o status e o proveito daqueles estudos:

A ACM. está á procura de homens para as posições mais altas na sua secretaria.

Se houvesse agora vinte novos peritos, já preparados haveria logares importantes para todos.

Se está interessado em preparar-se para ser secretario ou director de educação physica, dirija-se immediatamente a H. C. MELBY.

Rua da Quitanda, 47 - Caixa 254

Rio de Janeiro (Mocidade, 1923a, p. 14).

Passadas algumas edições da Mocidade, o anúncio sofre alterações e o que ganha destaque não mais é "uma profissão de futuro", mas o espaço que promoveria a formação para a carreira: o Instituto.

\section{INSTITUTO TECHNICO DA ASSOCIAÇÃO CHRISTÃ DE MOÇOS} ESCOLA DO RIO DE JANEIRO

Para a preparação de secretarios e directores da educação physica

Informações com o director

Rua da Quitanda, 47

Caixa 254

Rio de Janeiro (Mocidade, 1923b. p. 16).

Se a formação do secretariado na América do Sul produziu uma expectativa de que a Associação fosse conduzida por sujeitos com a nacionalidade do país em que a sede estava instalada, o anúncio dos primeiros diretores qualificados pelo Instituto Técnico parecia fomentar o intuito. Referindo-se aos alunos formados em 1925, a publicação da Asociación Cristiana de Jóvenes em Montevidéu informava que eles "se incorporan a la obra Sudamericana como los primeros secretarios nacionales para trabajar en colaboración con los secretarios extranjeros que tan fundamental, e intensa obra vienen realizando en estos países" (Boletin mensual Asociación Cristiana de Jóvenes, 1925, p. 3). Vestígios dessa incorporação podem ser encontrados em outro documento institucional que informa sobre a certificação de diretores de Educação Física formados pelo Instituto Técnico. Em uma breve apresentação para cada sujeito ali diplomado nos anos de 1925 e 1926, a Associação Cristã de Moços demarcava o trabalho em curso em alguma de suas sedes. São os casos de Henry Clark e Alfredo Wood, em 1925. O primeiro, brasileiro, era filho de Myron Clark, missionário da ACM no Brasil. Ao regressar ao país, depois da formação no Uruguai, assumiu como subdiretor do departamento físico da sede acemista no Rio de Janeiro. O segundo, argentino, ao encerrar os estudos no Instituto Técnico foi chamado para atuar como diretor de Educação Física da Associação em São Paulo. A mesma fonte informa que para o ano de 1926, Renato Eloy de Andrade, brasileiro, diplomou-se e que passou a ocupar o cargo de diretor físico da ACM em Porto Alegre 5 . Julio O'shanahan, argentino, concluiu o curso no Instituto Técnico e assumiu a função de 
subdiretor do Departamento Físico da Associação de Buenos Aires. Orestes Volpe, uruguaio, assumiu o departamento físico da sede em Montevidéu como diretor adjunto ${ }^{6}$.

A atenção à perspectiva inicial de ocupação de cargos acemistas foi compartilhada com circunstâncias dos contextos políticos nas décadas de 1920 e 1930 que reclamaram a definição de projetos educativos para a Educação Física, que extrapolavam questões intrínsecas à ACM. De modo similar a experiências uruguaias, no Brasil, para citar apenas traços da trajetória de um dos acemistas, Renato Eloy de Andrade foi nomeado como Inspetor de Educação Física de Minas Gerais, função que ocupou entre os anos de 1928 a 1937. Ali empreendeu esforços para a criação de playgrounds na cidade de Belo Horizonte e para a especialização de professoras do estado (Silva, 2017).

Vale ressaltar que, no país, a discussão de aspectos sobre a escolarização da Educação Física não contou apenas com a contribuição dos diretores físicos brasileiros, mas, também, acemistas estrangeiros estabeleceram fluxos profissionais a partir de um lugar que merece destaque: a Associação Brasileira de Educação (ABE). Por ocasião de um debate em torno de um anteprojeto que pretendia regulamentar o ensino de Educação Física no Brasil, enviado pelo Ministério da Guerra ao Congresso Nacional e de forte vínculo militar, a ABE, no ano 1929, forjou um inquérito no qual diferentes sujeitos foram consultados para responder um questionário. Nesse instrumento constavam quatro questões que interrogavam os métodos de Educação Física indicados para o ensino primário e secundário; a necessidade de professorado especializado para lecionar a matéria; a institucionalização da preparação em Educação Física; e a ação governamental no enfrentamento de questões relativas à disciplina. Foram consultados diretores da instrução pública, uma professora, um médico, militares, e sujeitos que mantiveram relação com a Associação Cristã de Moços, também produziram suas interpretações sobre o problema posto. James Summers, Emilio Chiapella, Henry Clark, Alfredo Wood, Oswaldo Diniz Magalhães (brasileiro, formado pelo Instituto Técnico em 1927), Alberto Regina (argentino, diplomado em 1927 pelo Instituto) ${ }^{7}$, Cyro de Moraes (brasileiro, formado pelo Instituto em 1929) ${ }^{8}$ e Hugo Grassi (que no ITSACJ ocupouse da matéria 'finanças da Associação Cristã de Moços') ${ }^{9}$, foram alguns diretores, com passagem pelas escolas de formação da Associação, que emitiram suas respostas para contribuição no inquérito.

São indícios do processo de partilha e disputa de sentidos para a Educação Física, não aquela circunscrita à Associação Cristã de Moços, mas a que se situava no debate de políticas educacionais.

\section{Considerações}

A intencionalidade inicial para o estabelecimento de uma formação em Educação Física no interior da Associação Cristã de Moços era a composição de seu próprio quadro de trabalho. É evidente nos cursos de especialização em Chicago e em Montevidéu a demanda pela compreensão da estrutura e da política interna da Associação, ainda que, em sua atuação, os diretores físicos que ali estudaram tenham promovido inventivos processos de apropriação a partir dos pertencimentos com instâncias nacionais e estaduais de educação que extrapolaram o trabalho na ACM. Ainda tendo por orientação os cargos acemistas, os estudos nos institutos de formação da Associação implicavam o contato com matérias sobre temas cristãos, necessidade que possivelmente se justifica pela marcada dimensão protestante que 
estruturava seu projeto formador. Além disso, os alunos tinham uma preparação técnica com acesso a conhecimentos biológicos e de administração, a saberes que permitissem o trato do jovem a partir de uma perspectiva social e missionária, e a diferentes práticas de exercícios físicos. Constituir-se como diretor de Educação Física pressupunha de antemão uma formação geral consistente, uma constituição corporal que atendesse parâmetros saudáveis e uma moral ilibada. Tais aspectos anunciam aproximações na formação em Chicago e em Montevidéu, que podem ser compreendidas como uma intencionalidade institucional. Não é acaso, quando da organização do Instituto Técnico, a promoção do contato com instituições, sujeitos, saberes nos Estados Unidos, como afirmado neste texto. Tais aproximações comportam também arranjos sutis nas formas de organização das matérias nos programas de ensino. Chama nossa atenção que no Instituto Técnico havia, explicitamente, estudos sobre a Educação Física em espaços institucionais que não apenas a ACM: as escolas e os liceus. Como processo de acomodação tal demarcação pode ser compreendida em função dos usos que os diretores físicos formados nas escolas de treinamento da Associação nos Estados Unidos vinham fazendo de sua qualificação: não apenas atuaram nas sedes da Associação, mas vincularam-se a projetos governamentais, à formação de professoras que seriam responsáveis pelo ensino de Educação Física. Ações que não eram inicialmente pensadas para os diretores físicos acemistas.

Vale destaque também a maior variedade de cursos de formação oferecida pelo Young Men's Christian Association College - administração geral, educação física, boy's work, county work, community work, industrial work, transportation work -, em relação ao Instituto Técnico, que promovia apenas os cursos de secretariado geral e de Educação Física. Dentre as especializações, a de Educação Física ter sido aquela promovida no Instituto Técnico pode constituir um indício sobre a importância que as intervenções no e sobre o corpo adquiriram no projeto de formação acemista.

Entendemos que estes foram negociados exercícios de sistematização por meio de conexões entre as instituições acemistas, que permitem conformar a formação de diretores físicos como lente para apreender os processos de circulação de saberes e conhecimentos na Associação. Ressalte-se também que extramuros da Associação, o movimento de formação de diretores físicos impactou a estruturação e o desenvolvimento da Educação Física nos países sul-americanos, com diferentes ênfases e modulações.

\section{Referencias}

\section{Bibliografia}

Ainsentein, A. \& Elías, L. (2018). Influencias de la YMCA en la cultura institucional del Instituto Nacional de Educación Física (INEF) Gral. Belgrano. Argentina, 19391967. Rev. Iberoam. Patrim. Histórico-Educativo, 4(1), 80-95. doi:10.20888/ridphe_r.v4i1.7859

Baia, A. \& Moreno, A. (2019). O papel do esporte no projeto formador das Associações Cristãs De Moços no Brasil (1903-1929). Movimento, 25, 01-11. doi: https://doi.org/10.22456/1982-8918.84997

Couchet, M.; Cabrera, G.; Dogliotti, P. \& Malán, P. (2013). La formación de directores de educación física en la etapa fundacional del Instituto Técnico de la Federación Sudamericana de Asociaciones Cristianas de Jóvenes. Revista

History of Education in Latin America - HistELA, v. 4, e25762, 2021, p. 12 de 15 
Universitaria de la Educación Física y el Deporte, 6(6), 43-54. Recuperado de http://www.revistasiuacj.edu.uy/index.php/rev1/article/view/56/53

Dogliotti, P. (2014). Discursividades sobre el Director de Educación Física en el Instituto Técnico Sudamericano de la ACJ. Educación Física y Ciencia, 16(2), 1-13. Recuperado

http://www.efyc.fahce.unlp.edu.ar/article/view/EFyCv16n02a02/6199

Dogliotti, P. (2015a). Educación del cuerpo y discursividades en torno a la formación en educación física en Uruguay (1874-1948). Montevideo, Uruguay: Comisión Sectorial de Investigación Científica (CSIC), Universidad de la República (Udelar).

Dogliotti, P. (2015b). Discursividades en la formación de docentes de educación física en el Uruguay: Jess T. Hopkins. Revista Teoria e Prática da Educação, 18(1), 123-133.

Recuperado de http://periodicos.uem.br/ojs/index.php/TeorPratEduc/article/view/29005/pdf_77

Dogliotti, P. \& Malán, P. (2015) La influencia protestante y del movimiento asociacionista de Springfield College en la educación del cuerpo y la educación física en el Uruguay. In L. Martínez Moctezuma (Coord.) Formando el cuerpo del ciudadano. Aportes para una historia de la educación física en Latinoamérica. (pp. 239-258). México: Universidad Autónoma del Estado de Morelos.

Fonseca, T. N. L. (2012). Mestiçagem e mediadores culturais e história da educação: contribuições da obra de Serge Gruzinski. In: Lopes, E. M. T. \& Faria Filho, L. M. (Orgs.), Pensadores sociais e História da Educação II (pp. 297-313). Belo Horizonte, MG: Autêntica.

Galak, E. (2019). La institucionalización del oficio de pedagogizar los cuerpos: el nacimiento de la formación profesional en educación física en Argentina (18971912). Revista História da Educação, 23, 1-29. doi: http://dx.doi.org/10.1590/2236-3459/79633

Gruzinski, S. (2015). O historiador e a mundialização. Texto apresentado na conferência ministrada em 11/06/2007, como participação no Programa Cátedras Fundação Ford. Belo Horizonte, MG: IEAT/UFMG.

Malán, P. (2017). Cristiandad Muscular y crisis del ethos valdense: Un estudio discursivo del ingreso del deporte a las Uniones Cristianas de Jóvenes de las colonias valdenses del Uruguay (1920 - 1970). (Tesis de Maestría) Facultad de Humanidades y Ciencias de la Educación, Universidad Nacional de la Plata, Argentina.

Malán, P. (2018). Cristiandad muscular y Asociación Cristiana de Jóvenes: la llegada del deporte a las colonias valdenses del Uruguay. Rev. Iberoam. Patrim. Histórico-Educativo, 4(1), 96-121, doi:10.20888/ridphe_r.v4i1.7856.

Malán, P. (2019). Gran Bretana, América del Norte y América del Sur: el transitar de la cristiandad muscular en occidente y su llegada al Uruguay (primera mitad siglo XIX). In Linhales, M.; Puchta, D.; Rosa, M. (Orgs.). Diálogos transnacionais na história da educação física. (pp. 169- 195). Belo Horizonte, M.G.: Fino Traço.

Scharagrodsky, P. (2006). El padre de la educación física argentina: fabricando una política corporal generiza da (1901-1938). In Á. AISENSTEIN \& P. Scharagrodsky Tras las huellas de la Educación Física escolar argentina. Cuerpo, género y pedagogía: 1880-1950. (pp. 159- 197). Buenos Aires, Argentina: Prometeo. 
Silva, G. C. (2017). A Associação Cristã de Moços e experiências de escolarização da Educação Física no Brasil: sujeitos, ideias e práticas acemistas em circulação (Tese de Doutorado). Faculdade de Educação, Universidade Federal de Minas Gerais, Belo Horizonte.

Silva, G. C. (2018). Um lugar de memória da Young Men's Christian Association: nos Kautz Family YMCA archives, os rastros sobre a formação de diretores físicos. Rev. Iberoam. Patrim. Histórico-Educativo, 4(1), 38-51. doi:10.20888/ridpher.v4i1.7857

Silva, G. C. da. (2019). Educação Física e formação docente no Brasil e no Uruguai: conexões a partir da Associação Cristã de Moços. In: Linhales, M.; Puchta, D.; Rosa, M. (Orgs.). Diálogos transnacionais na história da educação física. (pp. 123- 138). Belo Horizonte, M.G.: Fino Traço.

\section{Fontes}

Boletín mensual Asociación Cristiana de Jóvenes. (1925). dic., n. 88.

Comisión Nacional de Educación Física (CNEF). (1950). Biografía de un maestro. James Steward Summers, III Congreso Panamericano de Educación Física, Montevideo, Uruguay: CNEF.

Conard, F. (1959). Memorias de la Fundación de la Asociación Cristiana de Jóvenes de Montevideo, Montevideo, Uruguay: Asociación Cristiana de Jóvenes de Montevideo.

Ewald, C. J. (1921). Carta del 23 de diciembre de 1921 dirigida a los Secretarios Internacionales en Sudamérica. Montevideo, Uruguay: Federación Sudamericana de Asociación Cristiana de Jóvenes.

Federación Sudamericana de Asociaciones Cristianas de Jóvenes (FSACJ). (1923). Acta del 2 de febrero de 1923 de la Sesión Anual de la Junta Continental de la Federación Sudamericana de ACJ (FSACJ). Montevideo, Uruguay: Federación Sudamericana de Asociaciones Cristianas de Jóvenes (FSACJ).

Federación Sudamericana de Asociaciones Cristianas de Jóvenes (FSACJ). (1926). Instituto Técnico de las Asociaciones Cristianas de Jóvenes: Graduados de 1925 y 1926.

Federación Sudamericana de Asociaciones Cristianas de Jóvenes (FSACJ). (1927). Instituto Técnico de las Asociaciones Cristianas de Jóvenes: Diplomados de 1927.

Federación Sudamericana de Asociaciones Cristianas de Jóvenes (FSACJ). (1929). Instituto Técnico de las Asociaciones Cristianas de Jóvenes: Diplomados de 1929.

Hopkins, J. T. (1927). Quince años de Educación Física en las Asociaciones de América del Sur (1911-1926), Montevideo-Buenos Aires: Mundo Nuevo.

Instituto Técnico Asociación Cristiana de Jóvenes (ITACJ). (1922). Resumen de las clases desde 1922 a 1931: materias, horas de clases, puntos y clasificación. Instituto Técnico Asociación Cristiana de Jóvenes (ITACJ). (Inédito).

Instituto Técnico Asociación Cristiana de Jóvenes (ITACJ). (1947). Instituto Técnico de la Federación Sudamericana de Asociaciones Cristianas de Jóvenes: 
facultad de estudios para la preparación de los Secretarios - 25ํㅡㄹ Aniversario de su Fundación 1922 - 1947. Montevideo.

Mocidade, jun., n. 352, 1923a. p. 14.

Mocidade, set., n. 355, 1923b. p. 16.

Pereyra, J. (1946). Semblanza del Sr. Jess T. Hopkins. Montevideo: Centro Cultural de Profesores de Educación Física.

Young Men's Christian Association (YMCA). (1920). The Young Men's Christian Association College. Announcements for 1920-21. April, 1920. Box 114. George Williams College: an inventory of its records. Kautz Family YMCA Archives. University of Minnesota.

Young Men's Christian Association (YMCA). (1921). The Young Men's Christian Association College. Announcements for 1921-22. May, 1921. Box 114. George Williams College: an inventory of its records. Kautz Family YMCA Archives. University of Minnesota.

\section{Notas}

\footnotetext{
1 Jess T. Hopkins nasceu nos Estados Unidos em 31 de março de 1887. Ingressou no Internacional YMCA College de Springfield, Massachusetts, em 1906. Recebeu o diploma de bacharel em educação física e, posteriormente, de mestre em educação física. Em 1912 estabeleceu-se no Uruguai para assumir o Departamento de Educação Física da Associação Cristã de Moços de Montevidéu. Em 1913 foi nomeado diretor geral de Plazas Vecinales e, em seguida, diretor técnico da Comissão Nacional de Educação Física (CNEF, Uruguai), onde promoveu o estabelecimento de praças de esportes. A partir de 1919 ocupou o cargo de Diretor Continental de Educação Física da Federação Sul-Americana da ACM. Foi representante técnico na América do Sul do Comitê Olímpico Internacional (Pereyra, 1946). ${ }^{2}$ Ewald foi uma figura-chave na fundação da ACM em Montevidéu. Em 1908, quando ocupava o cargo de Secretário Associado da Associação de Buenos Aires, fez visitas a Montevidéu e se reuniu com membros do Clube Protestante. "En 1910 fue designado Secretario Viajante, para Sudamérica, del Comité Internacional y decidió establecer su oficina principal en Montevideo, por ser el mejor lugar y más apropiado para una organización internacional en Sudamérica" (Conard, 1959, p. 32). Foi um promotor do Instituto Técnico.

${ }^{3} \mathrm{Na}$ Argentina, destaca-se a formação criada em 1912, o Instituto Nacional Superior de Educação Física, a cargo do Dr. Enrique Romero Brest, de caráter "cívico-pedagógico" (Galak, 2019; Scharagrodsky, 2006). No Uruguai, é possível ressaltar os cursos de curta duração desenvolvidos pela CNEF entre 1920 e 1936. Embora muitos deles tenham sido coordenados e ditados por acemistas, os aspectos mais estritamente confessionais e de identidade da Associação Cristã de Moços foram retirados (Dogliotti, 2015a).

${ }^{4}$ No Uruguai, Campanha refere-se a todo interior do país, àqueles lugares que não se configuram como capital.

${ }^{5} \mathrm{Em}$ fontes brasileiras, não foi encontrada menção à passagem de Andrade pela ACM porto-alegrense. Os registros localizados indicam apenas sua vinculação à sede do Rio de Janeiro.

${ }^{6}$ Federación Sudamericana de Asociaciones Cristianas de Jóvenes, 1926.

7 Federación Sudamericana de Asociaciones Cristianas de Jóvenes, 1927.

${ }^{8}$ Federación Sudamericana de Asociaciones Cristianas de Jóvenes, 1929.

${ }^{9}$ Instituto Tecnico de la Federacion Sudamericana de Asociaciones Cristianas de Jóvenes (1947).
} 